\title{
Photovoltaic Performance of Dye-sensitized Solar Cells assembled with Hybrid Composite Membrane based on Polypropylene Non-woven Matrix
}

\author{
Yeon Jeong Choi and Dong-Won Kim* \\ Department of Chemical Engineering, Hanyang University, Seongdong-Gu, Seoul 133-791, Korea \\ ${ }^{*}$ E-mail: dongwonkim@hanyang.ac.kr \\ Received November 29, 2010, Accepted December 13, 2010
}

\begin{abstract}
Hybrid composite membranes were prepared by coating poly(ethylene oxide) and $\mathrm{SiO}_{2}$ particles onto the porous polypropylene nonwoven matrix. Gel polymer electrolytes prepared by soaking the hybrid composite membranes in an organic electrolyte solution exhibited ionic conductivities higher than $1.1 \times 10^{-3} \mathrm{~S} \mathrm{~cm}^{-1}$ at room temperature. Dyesensitized solar cell (DSSC) employing the hybrid composite membrane with $\mathrm{PEO}$ and $10 \mathrm{wt} \% \mathrm{SiO}_{2}$ exhibited an open circuit voltage of $0.77 \mathrm{~V}$ and a short circuit current of $10.78 \mathrm{~mA} \mathrm{~cm}^{-2}$ at an incident light intensity of $100 \mathrm{~mW} \mathrm{~cm}^{-2}$, yielding a conversion efficiency of 5.2\%. DSSC employing the hybrid composite membrane showed more stable photovoltaic performance than that of the DSSC assembled with liquid electrolyte.
\end{abstract}

Key Words: Dye-sensitized solar cell, Gel polymer electrolyte, Hybrid composite membrane, Photovoltaic performance, Polypropylene nonwoven

\section{Introduction}

Dye-sensitized solar cell (DSSC) has been considered as an alternative to a conventional silicon solar cell because of low cost, easy fabrication and relatively high conversion efficiency. ${ }^{1,2}$ It consists of a dye-sensitized nanoparticulated $\mathrm{TiO}_{2}$ electrode, an electrolyte containing redox couple and a Pt coated counter electrode. Such solar cells have conversion efficiencies reaching around $11 \%$, where the electrolyte usually used in the cells is an $\mathrm{I}^{-} / \mathrm{I}_{3}{ }^{-}$redox couple in organic solvents. ${ }^{3}$ However, the long-term durability of the cell is limited by the leakage or evaporation of the liquid electrolyte. Therefore considerable efforts have been made to replace the liquid electrolyte with polymer electrolyte, ${ }^{4-13}$ inorganic p-type semiconductors ${ }^{14}$ and organic hole transport materials. ${ }^{15,16}$ Among these approaches, use of the gel polymer electrolyte appears to give rise to successful results in terms of conversion efficiency. Conventional poly (ethylene oxide)(PEO)-based solid polymer electrolytes exhibit ionic conductivities ranging from $10^{-8}$ to $10^{-5} \mathrm{~S} \mathrm{~cm}^{-1}$ at room temperature, which is not sufficient for practical application at ambient temperature. In this respect, most of the recent studies have been directed to the preparation and characterization of gel polymer electrolytes which exhibit higher ionic conductivity at ambient temperature. Gel polymer electrolytes prepared by incorporating liquid electrolyte into a matrix polymer such as polyacrylonitrile(PAN), poly(vinylidene fluoride)(PVdF), poly (methyl methacrylate) (PMMA) and PEO have been employed in quasi-solid-state DSSCs. However, such gel polymer electrolytes suffer from poor mechanical strength, making assembly difficult and increasing the incidence of shorting between electrodes, because impregnation of liquid electrolyte into a polar polymer results in softening of the polymer. To overcome this problem, the porous separators such as microporous polyolefin membranes and nonwoven mats have been used as the supporting framework to make gel polymer electrolyte for lithium-ion batteries. ${ }^{17-20}$ Here the porous separator serves as the mechanical support, while gel polymer electrolyte coated onto the separator provides the necessary ionic conductivity between electrodes. To our knowledge, no gel polymer electrolytes supported by the porous separator have been reported so far for DSSC applications.

In our work, we prepared hybrid composite polymer membranes by coating $\mathrm{PEO}$ and $\mathrm{SiO}_{2}$ particles onto a porous polypropylene (PP) nonwoven matrix. PEO was useful as a coating material due to its ability to be easily gelled by the polar solvents. Highly conductive gel polymer electrolytes were then prepared by soaking the hybrid composite membrane in electrolyte solution containing $\mathrm{I}^{-} / \mathrm{I}_{3}^{-}$redox couple. In this paper, we report the photovoltaic performance of the dye-sensitized solar cells constructed with the gel polymer electrolyte using the hybrid composite membrane based on PP nonwoven matrix.

\section{Experimental}

Preparation of PEO-coated Composite Membrane. Appropriate amounts of PEO (MW: 100,000, Aldrich Chemical) was dissolved in an anhydrous dichloroethane. Different amounts $(0,5,10,15,20 \mathrm{wt} \%)$ of fumed silica (particle size: $14 \mathrm{~nm})$ were added to the polymer solution and uniformly dispersed by ball milling overnight. The mixture was further sonicated for $20 \mathrm{~min}$ to ensure complete homogeneity. The resulting solution was then coated onto both sides of a porous PP nonwoven fabric (Nippon Kodoshi Co., thickness: $29 \mu \mathrm{m}$, porosity: 70\%). After evaporation of dichloroethane for $10 \mathrm{~min}$ at room temperature, the hybrid composite membrane was vacuum dried at $80{ }^{\circ} \mathrm{C}$ for $24 \mathrm{hr}$. The thickness of the hybrid composite membrane was about $31 \mu \mathrm{m}$.

Electrode Preparation and Cell Assembly. Nanocrystalline $\mathrm{TiO}_{2}$ paste (Ti-Nanoxide T20/SP, Solaronix) was cast onto a fluorine-doped tin oxide (FTO) glass using a doctor blade and was then sintered at $450{ }^{\circ} \mathrm{C}$ for $30 \mathrm{~min}$. The $\mathrm{TiO}_{2}$ film formed on the FTO was $12 \mu \mathrm{m}$ thick and $5 \mathrm{~mm} \times 5 \mathrm{~mm}$ in size. It was 
sensitized overnight with a cis-diisothiocyanato-bis(2,2'-bipyridyl-4,4'-dicarboxylato)ruthenium (II) bis(tetrabutyl ammonium) (Ruthenium 535 bis-TBA, Solaronix) dye solution. Counter electrode was prepared by spin-coating $0.01 \mathrm{M} \mathrm{H}_{2} \mathrm{PtCl}_{6}$ in isopropanol onto the FTO glass and sintering at $450{ }^{\circ} \mathrm{C}$ for 30 min. A dye-sensitized solar cell was fabricated by sandwiching the hybrid composite membrane between a dye-coated nanoporous $\mathrm{TiO}_{2}$ electrode and a platinum counter electrode, and sealing the perimeter of the cell while pressurizing it. The membrane was gelled by filling liquid electrolyte into the cell through the holes on the counter electrode. The organic liquid electrolyte was composed of $0.5 \mathrm{M}$ lithium iodide (LiI), $0.05 \mathrm{M}$ $\mathrm{I}_{2}$ and $0.5 \mathrm{M}$ 4-tert-butylpyridine (TBP) in ethylene carbonate $(\mathrm{EC}) / \gamma$-butyrolactone $(\gamma$-BL) $(50: 50$ by volume). EC and $\gamma$-BL were used as organic solvent, because they have high dielectric constant and high boiling point, which are effective for solvating inorganic iodide and iodine, and reducing the evaporation of solvent in the cells. Upon injection of liquid electrolyte, the gelation of PEO occurred and the liquid electrolyte was trapped in the membrane. The electrolyte-injecting holes on the counter electrode were sealed by a sealant.

Measurements. The surface morphologies of $\mathrm{TiO}_{2}$ electrode, PP nonwoven fabric and hybrid composite membranes were examined using a scanning electron microscope (JEOL, JSM$6300)$. In order to measure ionic conductivity, the hybrid composite membrane was immersed in organic liquid electrolyte for $20 \mathrm{~min}$. The gelled membrane was sandwiched between two stainless steel (SS) electrodes. AC impedance measurements were then performed to measure ionic conductivity using an impedance analyzer over the frequency range of $10 \mathrm{~Hz}$ to 100 $\mathrm{kHz}$ with amplitude of $10 \mathrm{mV}$. Photovoltaic performance of DSSCs was evaluated using a xenon light source $\left(100 \mathrm{~mW} \mathrm{~cm}^{-2}\right)$ with an AM 1.5 filter in a solar simulator at ambient temperature. The light intensity was calibrated with a NREL-calibrated Si solar cell (PV Measurements Inc.). A black mask of $0.25 \mathrm{~cm}^{2}$ aperture was placed over the cells during irradiation.

\section{Results and Discussion}

Scanning electron micrographs of the surface of porous PP nonwoven and hybrid composite membranes are presented in Figure 1. The PP nonwoven fabric exhibits a highly porous three-dimensional web morphology formed by the interconnected fine fibers. As PEO and $\mathrm{SiO}_{2}$ powder were coated onto the PP nonwoven substrate, the $\mathrm{SiO}_{2}$ particles were covered with PEO, due to the high volumetric ratio of $\mathrm{PEO}$ to $\mathrm{SiO}_{2}$ powder. Due to the high porosity and large pore size of the PP nonwoven matrix, the coating materials $\left(\mathrm{PEO}\right.$ and $\left.\mathrm{SiO}_{2}\right)$ are readily impregnated into the $\mathrm{PP}$ nonwoven mat and fill up the uneven surface. As a result, the thickness of the hybrid composite membrane was not greatly increased after coating. Upon gelling with the liquid electrolyte, the polymer becomes a gel electrolyte and it in turn serves as an adhesive to bond the membrane and electrodes together, which meanwhile increases uptake and retention of the liquid electrolyte. In the hybrid composite membrane, PP nonwoven matrix could give enough mechanical integrity to the gel polymer electrolyte system.

Ionic conductivity of gel polymer electrolyte prepared by
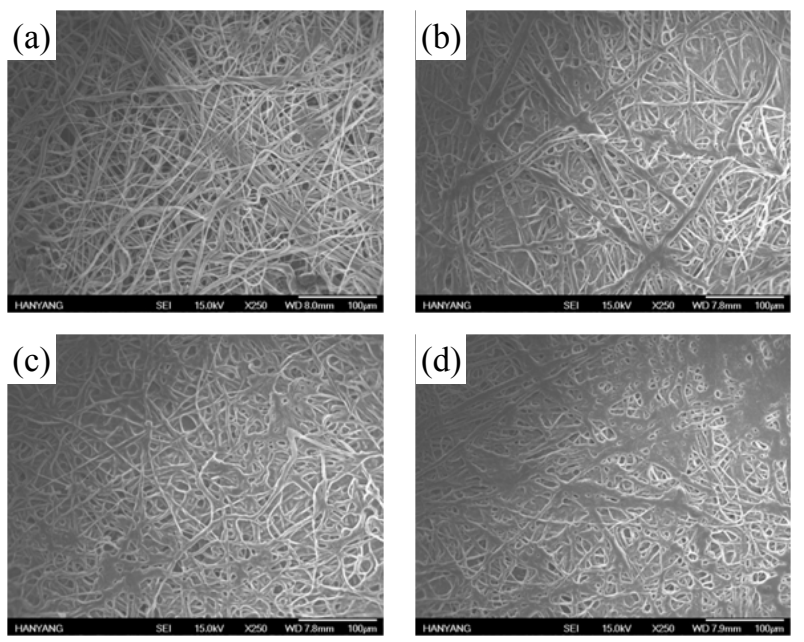

Figure 1. Scanning electron micrographs of the surface of (a) PP nonwoven and hybrid composite membranes coated by (b) PEO, (c) PEO and $10 \mathrm{wt} \% \mathrm{SiO}_{2}$, (d) PEO and $20 \mathrm{wt} \% \mathrm{SiO}_{2}$.

(a)

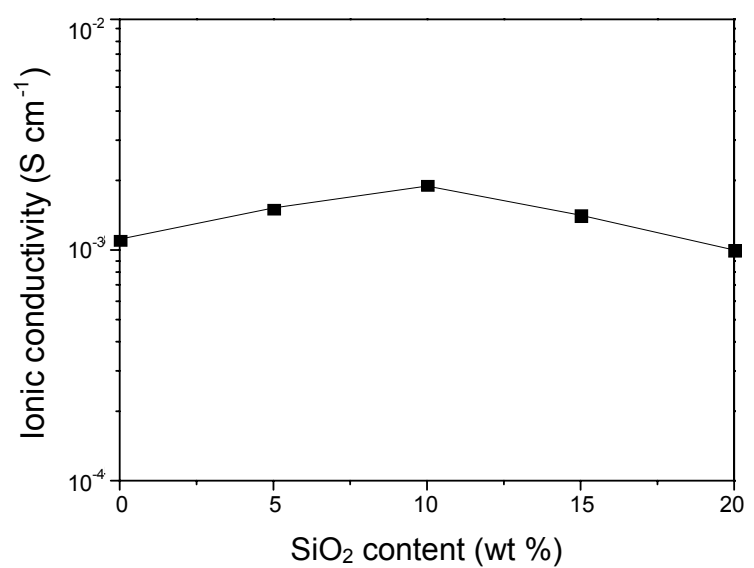

(b)

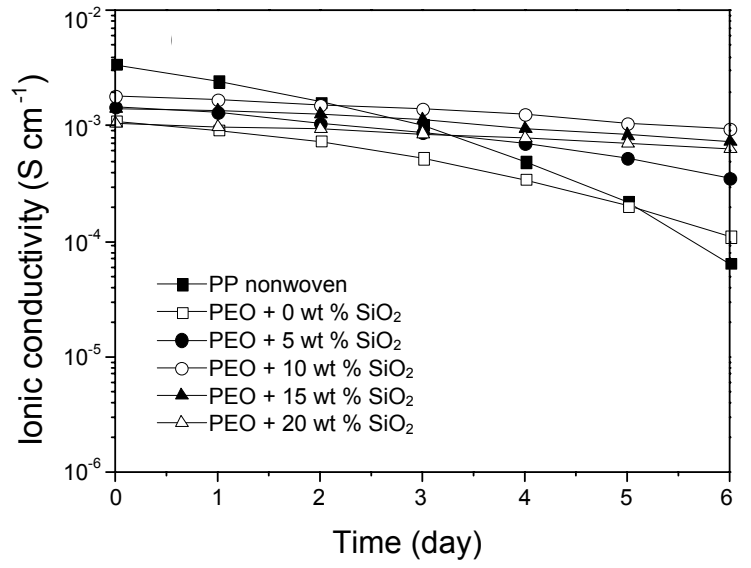

Figure 2. (a) Ionic conductivities of the gel polymer electrolytes prepared with different hybrid composite membrane, as a function of $\mathrm{SiO}_{2}$ content. (b) Ionic conductivities of electrolyte systems prepared with different membrane, as a function of storage time at $25^{\circ} \mathrm{C}$.

soaking the hybrid composite membrane in the electrolyte solution was measured. Figure 2-(a) shows the variation in ionic conductivities of the hybrid composite polymer electrolyte, as 
(a)

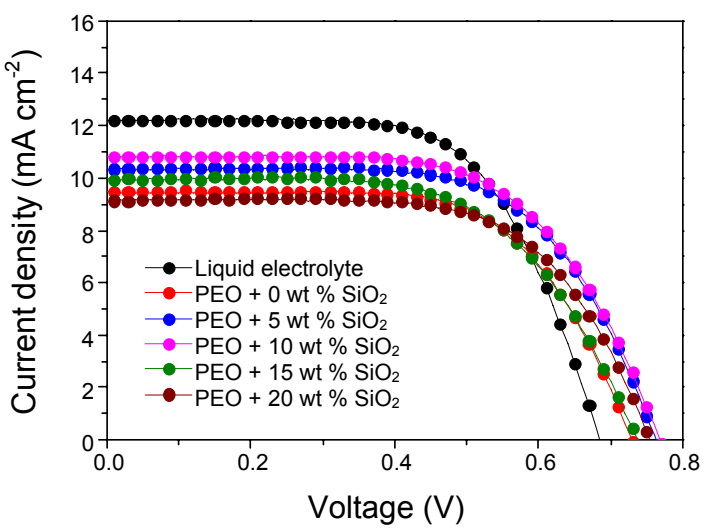

(b)

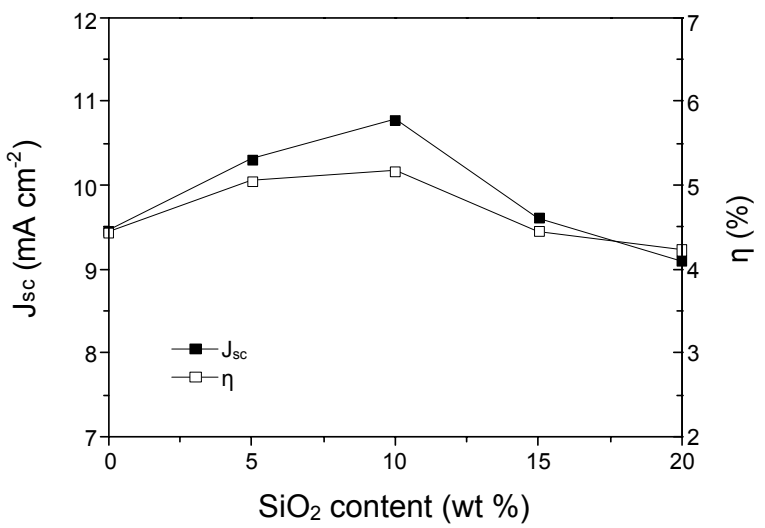

Figure 3. Effect of $\mathrm{SiO}_{2}$ content on the photovoltaic performances of DSSCs assembled with hybrid composite membranes: (a) photocurrentvoltage curves for DSSCs (AM 1.5, $100 \mathrm{~mW} \mathrm{~cm}^{-2}$ ), (b) $\mathrm{J}_{\mathrm{sc}}$ and $\eta v s$. $\mathrm{SiO}_{2}$ content.

a function of $\mathrm{SiO}_{2}$ content. Ionic conductivity increases with increasing content of $\mathrm{SiO}_{2}$ particle, reaching a maximum at $10 \mathrm{wt} \%$, followed by a decrease. An increase in ionic conductivity with the addition of $\mathrm{SiO}_{2}$ is related to both the generation of free volume at the interface of inorganic materials and the surface interaction between $\mathrm{SiO}_{2}$ and inorganic iodide, as previously reported. ${ }^{21,22} \mathrm{~A}$ decrease in ionic conductivity beyond $10 \mathrm{wt} \% \mathrm{SiO}_{2}$ may be attributed to the blocking effect on the transporting of charge carriers by the excessive $\mathrm{SiO}_{2}$ particles, since the $\mathrm{SiO}_{2}$ particle is a non-conducting material. Figure 2-(b) illustrates the time dependence of ionic conductivity for gel polymer electrolytes, as a function of storage time. It is clearly seen that the ionic conduction behavior with time is different for each membrane system. A gradual decrease in the ionic conductivity for the PP nonwoven-based electrolyte can be ascribed to the solvent exudation upon long storage, which arises from its poor compatibility with electrolyte solution due to the inherent hydrophobic properties of non-polar PP matrix. After the conductivity measurements, liquid electrolyte exuding from the PP nonwoven was observed in the cell. The PEO-coated PP membrane exhibited lower initial ionic conductivity than that of PP-based electrolyte, but its ionic conduction behavior with time was slightly improved. Moreover, as the $\mathrm{SiO}_{2}$ powder with PEO was coated onto the PP substrate, the stability of ionic conductivity with time was significantly improved, which indicates that an electrolyte solution is well encapsulated in the hybrid composite membrane. This result is related to the enhancement of retention capacity to hold liquid electrolyte, since $\mathrm{SiO}_{2}$ has a high adsorption capability and subsequently enables loading of the organic solvent, as authors previously reported. ${ }^{23}$

The photovoltaic performance of DSSCs assembled with hybrid composite membranes was evaluated. Figure 3-(a) represents the photocurrent density-voltage curves of the DSSCs assembled with the hybrid composite membranes coated by $\mathrm{PEO}$ and different content of $\mathrm{SiO}_{2}$. For comparison, the photocurrent density-voltage curve of the DSSC prepared with liquid electrolyte is also shown. The DSSCs assembled with the hybrid composite membranes exhibits a lower short circuit current density $\left(\mathrm{J}_{\mathrm{sc}}\right)$ and higher open circuit voltages $\left(\mathrm{V}_{\mathrm{OC}}\right)$ than the liquid electrolyte-based DSSC. Lower value of $\mathrm{J}_{\mathrm{SC}}$ in the DSSC with hybrid composite membrane originates from its lower ionic conductivity. Higher resistance for ion migration reduces the supply of $\mathrm{I}_{3}^{-}$to the Pt counter electrode, which causes the depletion of $\mathrm{I}_{3}^{-}$and also retards the kinetics of the dye regeneration, and therefore decreasing the $\mathrm{J}_{\mathrm{SC}}$. An increase of $\mathrm{V}_{\mathrm{OC}}$ in the DSSC is related to the reduction of charge recombination on the $\mathrm{TiO}_{2}$ and electrolyte interface. The injected electron in $\mathrm{TiO}_{2}$ is known to recombine with $\mathrm{I}_{3}{ }^{-}$in the electrolyte. If $\mathrm{I}_{3}{ }^{-}$ diffuse in a slower media like gel polymer matrix, the recombination reaction will be depressed, resulting in an increase of $\mathrm{V}_{\mathrm{OC}}$. This phenomenon can be also found in literatures published elsewhere. ${ }^{24-28}$ The increase of $\mathrm{V}_{\mathrm{oc}}$ may also result from the increase of $\mathrm{pH}$ value of the electrolyte by addition of $\mathrm{SiO}_{2}$, because the flat band potential of $\mathrm{TiO}_{2}$ shifts negatively with the increase of the basicity of the electrolyte, which results in an increase of $\mathrm{V}_{\mathrm{oc}}{ }^{29}{ }^{29}$ With addition of $\mathrm{SiO}_{2}$ into the electrolyte, the $\mathrm{pH}$ value increased from 5.94 (liquid electrolyte without $\mathrm{SiO}_{2}$ ) to values ranging from 7.25 to 7.64. $\mathrm{J}_{\mathrm{sc}}$ and conversion efficiency $(\eta)$ of the DSSC as a function of $\mathrm{SiO}_{2}$ content are shown in figure 3-(b). Both $\mathrm{J}_{\mathrm{sc}}$ and $\eta$ increased with $\mathrm{SiO}_{2}$ content up to $10 \mathrm{wt} \%$ and decreased with the further increase. An increase in $\mathrm{J}_{\mathrm{sc}}$ with $\mathrm{SiO}_{2}$ content is related to improved ionic conductivity of the electrolyte, as explained in Figure 2-(a). Thus, the optimum $\mathrm{SiO}_{2}$ content in the hybrid composite membrane to achieve the best conversion efficiency is $10 \mathrm{wt} \%$. The conversion efficiency $(5.17 \%)$ of the DSSC assembled with hybrid composite membrane containing PEO and $10 \mathrm{wt} \% \mathrm{SiO}_{2}$ is slightly lower than that of the corresponding liquid electrolytebased DSSC (5.35\%).

In order to evaluate the durability of photoelectrochemical performance for dye-sensitized solar cell, we measured the conversion efficiency with time. The cells were stored in a desiccator at ambient temperature and measured once a day under AM 1.5 irradiation. Figure 4 represents the variation of conversion efficiency as a function of time. The conversion efficiency in the liquid electrolyte-based DSSC decays continuously with time during the period of investigation. After 10 days, the cell lost $30 \%$ of its initial conversion efficiency, and it was lower than those exhibited by the DSSCs prepared with hybrid composite membranes. Gradual decrease of $\eta$ in the DSSC assembled with liquid electrolyte is related to the slow evaporation of liquid electrolyte. On the other hand, the conversion efficiencies of the DSSCs assembled with hybrid composite memb- 


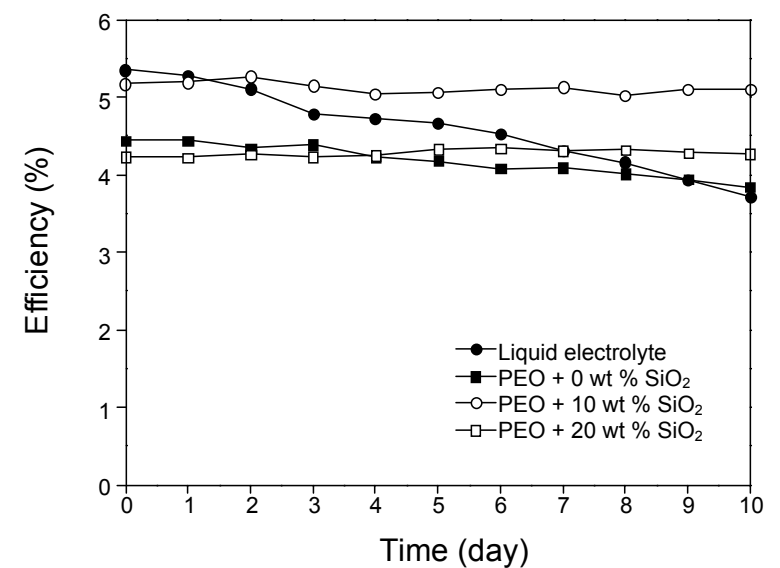

Figure 4. Variation of conversion efficiency as a function of time for the DSSCs assembled with liquid electrolyte and hybrid composite membranes.

rane coated by $\mathrm{PEO}$ and $\mathrm{SiO}_{2}$ remained almost constant. The cells kept more than $98 \%$ of their initial conversion efficiencies after 10 days. In the DSSC assembled with hybrid composite membrane, the organic solvent containing $\mathrm{I}^{-} / \mathrm{I}_{3}^{-}$redox couple is well encapsulated in the membrane, and the gel polymer formed in the membrane can promote strong interfacial contact between a dye-adsorbed $\mathrm{TiO}_{2}$ electrode and a platinum counter electrode, which give more stable performance than that of the DSSC assembled with liquid electrolyte.

\section{Conclusions}

Gel polymer electrolyte based on hybrid composite membrane coated by $\mathrm{PEO}$ and $\mathrm{SiO}_{2}$ particle was prepared by soaking the membrane in an organic electrolyte solution containing $\mathrm{I}_{3}{ }^{-} / \mathrm{I}^{-}$ redox couple. It encapsulated the electrolyte solution well in the cell and showed stable ionic conduction behavior that allowed application in the dye-sensitized solar cell. The addition of an appropriate amount of $\mathrm{SiO}_{2}$ particle into the hybrid composite membrane improved ionic conductivities. The optimum $\mathrm{SiO}_{2}$ content in hybrid composite membrane to achieve the highest conversion efficiency is $10 \mathrm{wt} \%$. Dye-sensitized solar cell employing the hybrid composite membrane coated by PEO and $10 \mathrm{wt} \% \mathrm{SiO}_{2}$ exhibited an open circuit potential of $0.77 \mathrm{~V}$ and a shirt circuit current of $10.78 \mathrm{~mA} \mathrm{~cm}^{-2}$ for an incident light intensity of $100 \mathrm{~mW} \mathrm{~cm}^{-2}$ yielding a conversion efficiency of $5.17 \%$, and better stability as compared to the DSSC with liquid electrolyte.

Acknowledgments. This work was supported by the Basic Science Research Program, through the National Research Foundation of Korea Grant (No. 2010-0001842) and the Korea Center for Artificial Photosynthesis, funded by the Ministry of Educa tion, Science, and Technology (MEST) through the National Research Foundation of Korea (NRF-2009-C1AAA001-20090093879).

\section{References}

1. O'Reagen, B.; Gratzel, M. Nature 1991, 353, 737.

2. Gratzel, M. Nature 2001, 414, 338.

3. Gratzel, M. J. Photochem. Photobiol. A: Chem. 2004, 164, 3.

4. Nogueira, A. F.; Durrant, J. R.; De Paoli, M.-A. Adv. Mater. 2001, 13,826 .

5. Stergiopoulos, T.; Arabatzis, I. M.; Katsaros, G.; Falaras, P. Nano Lett. 2002, 2, 1259.

6. Murai, S.; Mikoshiba, S; Sumino, H.; Hayase, S. J. Photochem. Photobiol. A: Chem. 2002, 148, 33.

7. Kim, Y. J.; Kim, J. H.; Kang, M. S.; Lee, M. J.; Won, J.; Lee, J. C.; Kang, Y. S. Adv. Mater. 2004, 16, 1753.

8. Kim, D. W.; Jeong, Y. B.; Kim, S. H.; Lee, D. Y.; Song, J. S. J. Power Sources 2005, 149, 112.

9. Kim, K. M.; Park, N. G.; Kang, M. G.; Ryu, K. S; Chang, S. H. Bull. Korean Chem. Soc. 2006, $27,322$.

10. Kang, M. S.; Oh, J. B.; Roh, S. G.; Kim, M. R.; Lee, J. K.; Jin, S. H.; Kim, H. K. Bull. Korean Chem. Soc. 2007, 28, 33.

11. Shim, H. J.; Kim, D. W.; Lee, C.; Kang, Y.; Suh, D. H. Macromol. Res. 2007, 16, 424.

12. Kim, S. R.; Parvez, M. K.; In, I.; Lee, H. Y.; Park, J. M. Electrochim. Acta 2009, 54, 6306.

13. Lim, S. J.; Kang, Y. S.; Kim, D. W. Electrochem. Commun. 2010 , $12,1037$.

14. Kumara, G. R. A.; Kaneko, S.; Okuya, M.; Tennakone, K. Langmuir 2002, 18, 10493.

15. Hagen, J.; Schaffrath, W.; Otschik, P.; Fink, R.; Bacher, A.; Schmidt, H.-W. Synth. Met. 1997, 89, 215.

16. Murakoshi, K.; Kogure, R.; Wada, Y.; Yanagida, S. Sol. Energy Mater. Sol. Cells 1998, 55, 113.

17. Kim, D. W.; Oh, B.; Park, J. H.; Sun, Y. K. Solid State Ionics 2000, $138,41$.

18. Kim, D. W.; Ko, J. M.; Chun, J. H.; Kim, S. H.; Park, J. K. Electrochem. Commun. 2001, 3, 535.

19. Song, M. K.; Kim, Y. T.; Cho, J. Y.; Cho, B. W.; Popov, B. N.; Rhee, H. W. J. Power Sources 2004, 125, 10.

20. Jeong, Y. B.; Kim, D. W. J. Power Sources 2004, 128, 256.

21. Wang, H.; Li, H.; Xue, B.; Wang, Z.; Meng, Q.; Chen, L. J. Am. Chem. Soc. 2005, 127, 6394.

22. Kang, M. S.; Kim, J. H.; Won, J.; Kang, Y. S. J. Phys. Chem. C 2007, $111,5222$.

23. Kim, D. W.; Sun, Y. K. J. Electrochem. Soc. 1998, 145, 1958.

24. Liu, Y.; Hagfeldt, A.; Xiao, X.-R.; Lindquist, S.-E. Sol. Energy Mater. Sol. Cells 1998, 55, 267.

25. Scully, S. R.; Lloyd, M. T.; Herrera, R.; Giannelis, E. P.; Malliaras, G. G. Synth. Met. 2004, 144, 291.

26. Zhang, X.; Yang, H.; Xiong, H. M.; Li, F. Y.; Xia, Y. Y. J. Power Sources 2006, 160, 1451.

27. Wei, T. C.; Wan, C. C.; Wang, Y. Y. Sol. Energy Mater. Sol. Cells 2007, 91, 1892.

28. Priya, A. R. S.; Subramania, A.; Jung, Y. S.; Kim, K. J. Langmuir 2008, 24, 9816.

29. Suresh, T.; Joseph, J.; Son, K. M.; Vittal, R.; Lee, J.; Kim, K. J. Sol. Energy Mater. Sol. Cells 2007, 91, 1313. 